\title{
Publisher Correction to: Dynamic boundary conditions and the Carslaw-Jaeger constitutive relation in heat transfer
}

\section{Niko Sauer ${ }^{1}$}

Published online: 26 January 2021

(C) Springer Nature Switzerland AG 2021

\section{Publisher Correction to: SN Partial Differ. Equ. Appl. https://doi.org/10.1007/s42985-020-00050-y}

Unfortunately systematic LaTex mistakes appeared in this article.

They all stem from failure to close braces in the LaTeX command Imathfrak $\{D\}$. The closing brace $\}$ was either left out of put in the wrong place. These mistakes render the article almost unreadable.

The original article has been corrected.

The original article can be found online at https://doi.org/10.1007/s42985-020-00050-y.

$\triangle$ Niko Sauer

niko.sauer@up.ac.za

1 Centre for the Advancement of Scholarship, University of Pretoria, Pretoria, South Africa 